\title{
Chapter 7 \\ Effects of "Clean Feeding" Management on Livestock Products Contaminated with Radioactive Cesium Due to the Fukushima Daiichi Nuclear Power Plant Accident
}

\author{
Noboru Manabe, Tomotsugu Takahashi, Maiko Endo, Chunxiang Piao, \\ Junyou Li, Hiroshi Kokado, Minoru Ohta, Keitaro Tanoi, \\ and Tomoko M. Nakanishi
}

\begin{abstract}
Contamination of food and animal products by radioactive cesium represents an important potential route of exposure in the human food chain. Therefore, following the Fukushima Daiichi nuclear power plant accident, the development of solutions for radiocesium contamination is a serious social issue in Japan. Most farm animals are kept in closed barns in Japan; this reduced the initial contamination of animal products by radioactive nuclides in the early phase of the accident. Furthermore, pigs and chickens were given imported feed that was not contaminated. However, more than 10 million tons of grass feed were needed for herbivorous livestock in Japan. We report the effects of "clean feeding" management on livestock products contaminated with radioactive cesium due to the nuclear accident. The present results concerning products from herbivores (horses, sheep, and cattle) revealed that radiocesium levels were undetectable in the meat or milk of herbivores that fed on non-contaminated feed after an initial period of consuming radiocesium-contaminated feed. Thus, we conclude that
\end{abstract}

\footnotetext{
N. Manabe $(\bowtie)$

Animal Resource Science Center, Graduate School of Agricultural and Life Sciences, The University of Tokyo, Kasama 319-0206, Japan

Osaka International University, Osaka 570-8555, Japan

e-mail: n-manabe@oiu.jp

T. Takahashi • M. Endo • C. Piao • J. Li

Animal Resource Science Center, Graduate School of Agricultural and Life Sciences, The University of Tokyo, Kasama 319-0206, Japan

H. Kokado • M. Ohta

Miho Training Center, Japan Racing Association, Ibaraki 300-0415, Japan

K. Tanoi • T.M. Nakanishi

Radioisotope Center, Graduate School of Agricultural and Life Sciences, The University of Tokyo, Tokyo 113-8657, Japan
} 
"clean feeding" management can play a crucial role in solving the social problem of food contamination.

Keywords Cattle $\bullet$ Clean feeding $\bullet$ Feeding management $\bullet$ Herbivorous livestock $\bullet$ Horses $\bullet$ Sheep $\bullet$ Radioactive cesium $\bullet$ The Fukushima Daiichi nuclear power plant accident

\subsection{Introduction}

On March 11th, 2011, the Japanese Prime Minister declared that a nuclear disaster occurred at Fukushima Daiichi nuclear power. This disaster resulted from an earthquake that occurred in Eastern Japan. The Japanese government subsequently issued various correspondences, and on March 17, 2011, the Ministry of Health, Labor and Welfare, Japan (MHLW) was notified of the handling of foods that were contaminated with radionuclides (hereafter referred to as radioactive cesium). They established provisional radionuclides reference/regulation levels for food and drinking water, under the guide of food sanitation law. Radioactive cesium levels (cesium137 and cesium-134) in drinking water, milk, and dairy products had to be less than $200 \mathrm{~Bq} / \mathrm{kg}$, while those in other foods, including cereals, vegetables, fruits, meat, eggs, and fish had to be less than $500 \mathrm{~Bq} / \mathrm{kg}$. In response to the provisional reference/ regulation values, the Ministry of Agriculture, Forestry and Fisheries, Japan (MAFF) negotiated a rule that prevented food contamination by radionuclides. On April 14, 2011, the MAFF established regulations to reduce radioactive cesium contamination in livestock and livestock products such as milk and meat. Radioactive cesium levels in feed for dairy cattle, beef cattle, horses, pigs and chickens had to be less than 300 and feed for farmed fish had to be less than $100 \mathrm{~Bq} / \mathrm{kg}$. The provisional reference/ regulation values were subsequently evaluated from various angles, and radioactive cesium levels in human food and drinking water were significantly revised. New reference/regulation values were applied on April 1, 2012. Therefore, radioactive cesium levels had to be maintained at less than $10 \mathrm{~Bq} / \mathrm{kg}$ in drinking water, less than $50 \mathrm{~Bq} / \mathrm{kg}$ in milk and infant foods, and less than $100 \mathrm{~Bq} / \mathrm{kg}$ in other foods (such as cereals, vegetables, fruits, meat, eggs, and fish). These reference/regulation values are still applicable today. In response to such revisions, on February 3, 2012 the MAFF also revised radioactive cesium levels in livestock feed and bedding, and fertilizers such as compost used in crop production. However, these revised values were considered insufficient to meet the new reference values for human foods. Therefore, the MAFF established further revisions on March 23, 2012, which were referred to as new tolerance values. With these new tolerance levels, radioactive cesium levels had to be less than $100 \mathrm{~Bq} / \mathrm{kg}$ in feeds for cattle and horse, $80 \mathrm{~Bq} / \mathrm{kg}$ in pig feed, $160 \mathrm{~Bq} /$ $\mathrm{kg}$ in chicken feed, and $40 \mathrm{~Bq} / \mathrm{kg}$ feed for farmed fish. Moreover, radioactive cesium levels in the litters of livestock and fertilizer containing compost had to be less than $400 \mathrm{~Bq} / \mathrm{kg}$. 
The reference/regulation values for human foods and tolerance values for animal feeds were established immediately after the Fukushima Daiichi nuclear power plant accident, and were based on overseas findings, not those in Japan. Farming systems in Japan differ from those in overseas countries. Japanese people have characteristic eating habit and farming systems; therefore, fundamental research that reflects the reality of these Japanese styles needs to be considered when these reference/regulation and tolerance values are revised.

After the nuclear power plant accident, researchers in Japan performed empirical research using livestock under conditions that reflected feed management in Japan in order to determine and subsequently alleviate radioactive cesium contamination levels in agricultural areas. We investigated how the levels of radioactive cesium migrated from feed to livestock and livestock products using farm animals under conditions that reflected the realities of feeding management in Japan in an attempt to maintain the health of the Japanese population. It is approximately 4 years since the nuclear power plant accident, and many of our research activities are ongoing. Although most of our findings are incomplete or are only provided as interim reports, we hope that the results described herein will contribute to the reconstruction of the livestock industry after the Fukushima Daiichi nuclear power plant accident.

\subsection{Absorption and Accumulation of Radioactive Cesium from Feed to Horse Meat and the Effect of "Clean Feeding" Management}

In mid-March, 2011, livestock feeds (such as grass and rice straw) were contaminated with radionuclides including radioactive cesium. Contamination occurred over wide areas of Tohoku and Kanto, with a radius of approximately $200 \mathrm{~km}$ from the Fukushima Daiichi nuclear power plant. However, the dynamics of radioactive cesium from contaminated feeds to farm animals have not yet been elucidated in detail. Radioactive cesium-contaminated horse meat was found in November, 2012. Radioactive cesium $(115.6 \mathrm{~Bq} / \mathrm{kg}$ ) was detected in horse meat processed at a local slaughterhouse (Koriyama-city, Fukushima prefecture, Japan) approximately $60 \mathrm{~km}$ from the nuclear power plant at a level that slightly exceeded the new reference/regulation value $(100 \mathrm{~Bq} / \mathrm{kg})$. Following this incident, we investigated the transition of radioactive cesium from feed to horse meat using contaminated grass haylage produced at an experimental ranch of the Animal Resource Science Center, the University of Tokyo (Kasama, Japan) in the spring of 2011. The fate of radioactive cesium in horse meat after initiating a diet of non-contaminated grass haylage was assessed. 


\subsubsection{Experimental Procedure}

(A) Preparation of horse feed containing radioactive nuclides caused by the accident at the Fukushima Daiichi nuclear power plant: Grass (Italian ryegrass, Lolium multiflorum Lam.) was seeded in October 2010 and was cultivated in a grass field at the experimental ranch of the Animal Resource Science Center. After mowing between the 10th and 15th of May, 2011 (2 months after the accident), raw grass (radioactive iodine: undetectable levels, and radioactive cesium: $113 \mathrm{~Bq} / \mathrm{kg}$ ) was dried for several days and then packed into plastic film to prepare anaerobically fermented grass forage (haylage). The haylage contained radioactive nuclides (radioactive iodine: undetectable level and radioactive cesium: $480 \mathrm{~Bq} / \mathrm{kg}$ ).

(B) Horse feed without radioactive nuclides: we used haylage that was produced in May 2013 at the Animal Resource Science Center. This haylage contained undetectable levels of iodine or cesium. Horses were fed the non-contaminated haylage and mixture feed $(0.5 \mathrm{~kg} / 400 \mathrm{~kg}$ of body weight/day) purchased from JRA Facilities Co., Ltd. (Tokyo, Japan) depending on the physical condition of the horses.

(C) A study to assess the effects of "clean feeding" management: Six horses (male and female, 3-4 years old) that were kept in the stables of the Animal Resource Science Center were used. They were fed only non-contaminated haylage $(10 \mathrm{~kg} / 400 \mathrm{~kg}$ of body weight/day) for 4 weeks before being examined in June 2013 ( $380 \pm 28 \mathrm{~kg}$ body weight at the end of pre-feeding, $\mathrm{n}=6)$. These horses were then given contaminated haylage $(10 \mathrm{~kg} / 400 \mathrm{~kg}$ of body weight/ day) for 8 weeks $(404 \pm 39 \mathrm{~kg}$ body weight at the end of feeding, $\mathrm{n}=6$ ) followed by "clean feeding" with non-contaminated haylage and mixture feed for 4 weeks ( $391 \pm 38 \mathrm{~kg}$ body weight at the end of feeding, $\mathrm{n}=6$ ), 8 weeks ( $388 \pm 13 \mathrm{~kg}$ body weight at the end of feeding, $\mathrm{n}=4)$, and 16 weeks ( $371 \pm 15 \mathrm{~kg}$ body weight at the end of feeding, $\mathrm{n}=2$ ). During the study period, each horse's feed intake was measured daily. The horses were given free access to water, which contained undetectable levels of iodine or cesium, through automated system. Following the administration of radioactive cesium-contaminated haylage, and 4 and 8 weeks after the initial administration of non-contaminated haylage, glutei skeletal muscle samples were collected by biopsy under sedation and local anesthesia. We sacrificed two horses each at 4,8 , and 16 weeks after the initial administration of non-contaminated haylage, under general deep anesthesia. We collected samples from the heart, spleen, liver, kidney, and psoas major muscle to estimate radioactive cesium contamination and conventional histopathology. Blood and feces were also collected. The radioactivity of iodine-131, cesium-134, and cesium-137 in each horse was measured biweekly. The body weight of each horse was measured every 4 weeks. During the experiment, a veterinarian diagnosed the health status of the horses, and conducted blood biochemical tests and hematological analyses using automatic analyzers every 4 weeks. 
(D) Measurement of radioactive elements: The concentrations of radioactive elements in each sample were measured using a germanium semiconductor detector, and each nuclide was identified by gamma-ray spectrometry. Cesium-134 and cesium-137 were quantified at 661.6 and $604.7 \mathrm{keV}$, respectively, and each $\mathrm{Bq}$ value was calculated by calibrating the count value. Each radionuclide concentration was calculated based on the weight of each sample. The detection limit was set to three times the standard deviation of the background radiation level(s).

\subsubsection{Results}

(A) Body weight and feed intake: No significant differences were observed in body weight or feed intake of animals between the non-contaminated haylage feeding period and the contaminated haylage feeding period (data not shown).

(B) Health status: No serious symptoms were noted in any horse during the non-contaminated haylage feeding period or contaminated haylage feeding period. Furthermore, no significant differences were observed in blood biochemical parameters or hematological parameters between the non-contaminated haylage feeding period and contaminated haylage feeding period (data not shown).

(C) Changes in radiocesium levels in skeletal muscle, blood, and feces: The concentrations of radiocesium in the glutei skeletal muscle increased to 78-151 (113 \pm 29$) \mathrm{Bq} / \mathrm{kg} 8$ weeks after the start of contaminated haylage feeding (Table 7.1). After ceasing administration of the contaminated forage, the concentration of radiocesium in the glutei skeletal muscle of horses, with the exception of one animal, decreased after 4 weeks, and $30 \mathrm{~Bq} / \mathrm{kg}$ of radioactive cesium remained in the glutei skeletal muscle of this one horse. No detectable levels of radioactive cesium were noted in the glutei skeletal muscle of any horses 8 weeks after the initiation of the non-contaminated haylage administration. During the experiments, no detectable levels were found in blood samples. However, 95-136 (118 \pm 14 ) and 234-290 $(255 \pm 20) \mathrm{Bq} / \mathrm{kg}$ were detected in feces samples at 4 and 8 weeks, respectively, after the start of contaminated haylage feeding. Radiocesium levels in the muscle of horses were slightly lower for horses with high levels of cesium in their feces. We suggest that the absorption capacity of radioactive cesium differs between individual horses.

(D) Changes in radiocesium levels and histopathological findings in horse organs: Two horses were sacrificed at 4, 8, and 16 weeks after the initial administration of non-contaminated haylage, and heart, spleen, liver, kidney, and psoas major muscle samples were collected for radioactive cesium measurements and histopathological evaluations. As shown in Table 7.2, no radiocesium was detected in heart, spleen, liver, kidney, or psoas major muscle samples at any time. Moreover, there were no notable histopathological findings in any horse organs (data not shown). 


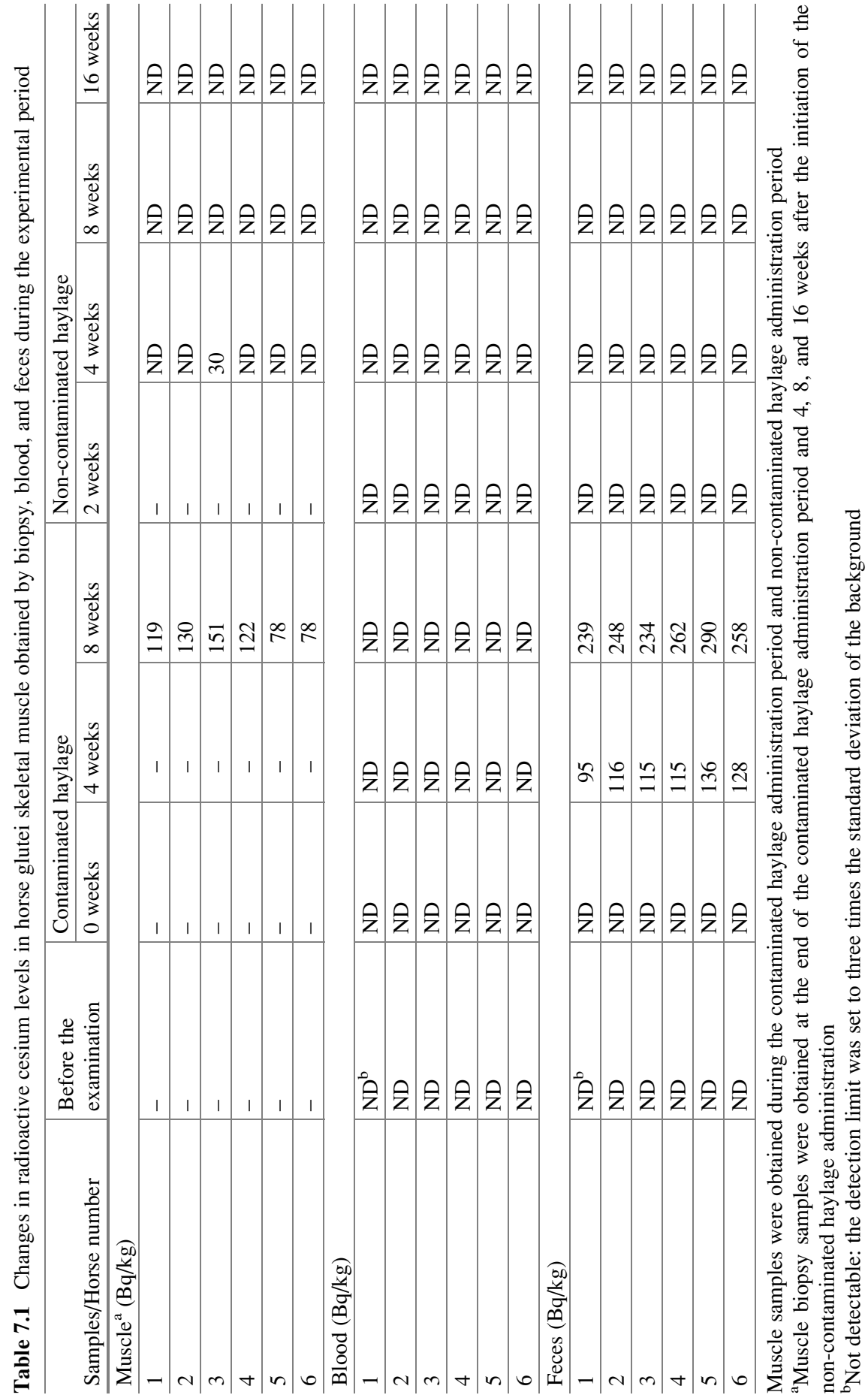


Table 7.2 Radioactive cesium levels in the heart, spleen, liver, kidney, and psoas major muscle when animals were sacrificed 4,8 , and 16 weeks after the initiation of the non-contaminated haylage administration

\begin{tabular}{l|l|l|l|l|l|l}
\hline \multirow{2}{*}{ Horse number } & Sacrifice time $^{\mathrm{a}}$ & \multicolumn{5}{l}{ Radioactive cesium level (Bq/kg) } \\
\cline { 2 - 7 } & (weeks) & Heart & Spleen & Liver & Kdney & Psoas major muscle \\
\hline 1 & 4 & ND $^{\mathrm{b}}$ & ND & ND & ND & ND \\
\hline 2 & 4 & ND & ND & ND & ND & ND \\
\hline 3 & 8 & ND & ND & ND & ND & ND \\
\hline 4 & 8 & ND & ND & ND & ND & ND \\
\hline 5 & 16 & ND & ND & ND & ND & ND \\
\hline 6 & 16 & ND & ND & ND & ND & ND \\
\hline
\end{tabular}

${ }^{a}$ Horses were sacrificed 4,8 and 16 weeks after the initiation of the non-contaminated haylage administration

${ }^{\mathrm{b}}$ Not detectable: the detection limit was set to three times the standard deviation of the background

\subsubsection{Discussion and Conclusion}

Horses (body weight $\sim 400 \mathrm{~kg}$ ) were fed with radiocesium (4800 Bq/400 kg of body weight/day) for 8 weeks, and subsequently radiocesium was detected in their glutei skeletal muscles $(113 \pm 29 \mathrm{~Bq} / \mathrm{kg})$. Radiocesium could not be detected in these muscles 8 weeks after ceasing administration of the contaminated feed.

We examined the new tolerance level of radioactive cesium values in feed for horses (less than $100 \mathrm{~Bq} / \mathrm{kg}$ ). We confirmed that when horses were fed for 8 weeks with haylage contaminated with radioactive cesium at a level that was approximately 5 times higher $(480 \mathrm{~Bq} / \mathrm{kg})$ than the new tolerance value, radiocesium levels in the horse meat were not high $(113 \pm 29 \mathrm{~Bq} / \mathrm{kg})$. The concentrations of radiocesium in the skeletal muscles of some horses were lower than the new reference/regulation level set by the Japanese Government $(100 \mathrm{~Bq} / \mathrm{kg}$ for radiocesium). Horses were subsequently given feed containing no radiocesium, and the concentrations of radiocesium in the muscles rapidly decreased. Concentrations of radiocesium 4 weeks after ceasing the feeding of contaminated forage decreased to background levels of less than $5 \mathrm{~Bq} / \mathrm{kg}$ in 5 horses, but not in one horse.

Our results indicate that if farmers provide feed with radiocesium levels that are less than the new tolerance value, the radiocesium levels in horse meat will always be less than the new reference/regulation level. Moreover, if farmers give horses feed containing higher levels of radiocesium than the new reference/regulatory value, then they if they keep these horses on a non-contaminated diet for the same period of time that the horses were given the contaminated feed, then the radiocesium should be reduced to allowable levels in the meat.

There were two main routes of radionuclide contamination of farm animals after the nuclear accident: inhalation and ingestion of contaminated feed and/or water. Beresford and Howard (2011) reported that inhalation and water intake by animals were the most important routes in the early phase of the nuclear accident. However, 
at the ranch of the Animal Resource Science Center (approximately $140 \mathrm{~km}$ southwest from the Fukushima Daiichi nuclear power plant), the concentration of radionuclides in the air was not at a detectable levels 2 months after the accident. No radionuclide contamination was detected in drinking water. Intake via water was previously shown to be a small contributor (Nisbet et al. 2010). Therefore, in the present study the most important pathway for horses was identified as the ingestion of radionuclide-contaminated feed.

The degree of absorption from the gastrointestinal tract is an important factor that determines radiocesium levels in animal tissues. In the case of radiocesium, the source of ingested radiocesium is a major factor determining subsequent concentrations in tissues, with the true absorption coefficient ranging from 0.10 to 0.80 (Howard et al. 2001). That study showed that the absorption levels of radiocesium particles and soil binding radiocesium were lower than that of radiocesium incorporated within plants. In the present study, grass was grown for approximately 2 months after the nuclear accident, harvested, dried, and prepared for haylage. The fermented grass forage used in the present study may have contained particles of radiocesium fallout, radiocesium bound to soil, and radiocesium incorporated within the plant tissues. As described above, extremely low or undetectable levels of radiocesium were noted in blood samples, whereas increasing levels of radiocesium $(118 \pm 14$ and $255 \pm 20 \mathrm{~Bq} / \mathrm{kg}$ at 4 and 8 weeks after the initial feeding of contaminated haylage, respectively) were found in feces samples. Although body weights did not change in horses given a certain amount of radiocesium in haylage during the experimental period, radiocesium levels increased in their feces. Furthermore, radiocesium levels were low in the muscles of horses with high radiocesium levels in their feces. This result indicated that the absorption capacity of radioactive cesium differed among individual horses. We previously reported differences in radiocesium metabolism among individual cows (Hashimoto et al. 2011; Manabe 2012; Manabe et al. 2011, 2013, 2014; Takahashi et al. 2012). These cows were given radiocesium-contaminated feed, and once the cows were removed from radiocesium-contaminated forage, radiocesium concentrations in their milk rapidly decreased. The rate by which radioactive nuclides was lost from milk was termed the biological half-life, which is defined as the time required for the radionuclide activity concentration in milk to be reduced by one half excluding physical decay. The uptake and loss rates of radionuclides varied among cows and tissues. The biological half-life for radiocesium has been associated with the metabolic turnover rate of cesium. Changes in radiocesium levels in milk after the Chernobyl nuclear power plant accident were summarized by the International Atomic Energy Agency (IAEA) (2005). The rate of decline in radionuclide activity concentrations in milk of different species of dairy ruminants was rapid. The half-life of radiocesium in various milk sources range 0.5-3.5 days. These values were consistent with our result (approximately 2.0 days). The biological half-life of radiocesium in animals is an important factor influencing the effectiveness and practicality of many countermeasures targeting animal-derived foodstuffs, including decontamination using "clean feeding" or cesium binders. 
In order to scientifically understand the phenomenon of radiocesium in horses, more detailed research is needed on the absorption of radiocesium from feed, its accumulation and distribution in the body, its pharmacokinetics, and the mechanisms underlying its excretion from the body. In the present study, we did not examine changes in radioactive strontium-90, which accumulates in bones and plays a role as a carcinogenic factor in meat. Further research on transfer kinetics and the coefficient of strontium- 90 from forage contaminated by the fallout from the Fukushima Daiichi nuclear power plant accident to horse meat is also required.

Moreover, the present results involved the initial phase of the accident; therefore, further research is needed to remediate livestock management for radiocesium contamination under the existing exposure conditions, as follows.

1. Improvements in pasture: Feasible and suitable surface improvements in grassland and radical improvements in meadow methods for Japanese farming practices should be developed to reduce radiocesium contamination in grassland.

2. Reductions in radiocesium intake: Feasible and suitable agents should be explored to prevent gut absorption by administering radiocesium binding agents to animals. The effectiveness and feasibility of adding candidate binding compounds to fodder such as clay minerals (bentonites, vermiculites, and zeolites) that adsorb cesium ions, to reduce the gut uptake of radiocesium by farm animals have been evaluated. The effectiveness and feasibility of the addition of hexacyanoferrate to feedstuffs has also been determined. The hexacyanoferrate compound, Prussian blue, is a radiocesium binder that is added to farm animal feed to reduce the transfer of radiocesium to animal products by reducing its absorption in the gut (IAEA 1997). Ammonium-hexacyanoferrate (AFCF), the commonly used form for remediation, was used extensively after the Chernobyl accident in Russia, Ukraine, and Belarus as well as in western European countries, including Norway and Sweden, and was shown to be very effective for animal use (Pearce 1994; Nisbet et al. 2010). Moreover, the acceptability of these strategies for Japanese farmers also needs to be investigated.

3. Collateral safety of animal products: "clean feeding" management has been considered feasible and suitable for the production of animal products without disrupting normal farming practices. Farm animals are provided with uncontaminated feed or forage with acceptable levels of radiocesium. To prevent the radiocesium contamination of animal products by ensuring that feedstuffs that are too highly contaminated are not ingested by farm animals, a registration system to identify individual farm animals should be developed.

In conclusion, the results of the present study demonstrate that when horses receive less than $500 \mathrm{~Bq} / \mathrm{kg}$, they produce meat contaminated with approximately $100 \mathrm{~Bq} / \mathrm{kg}$ radiocesium, and that "clean feeding" can reduce radiocesium contamination levels in meat. 


\subsection{The Effects of "Clean Feeding" Management on Sheep Meat: Removal of Radioactive Cesium Due to the Nuclear Power Plant Accident from Mutton}

One hundred sheep (50 male and 50 female), which had been kept in a paddock or livestock barn in the central area of Fukushima Prefecture (approximately $60 \mathrm{~km}$ from the Fukushima Daiichi nuclear power plant) for approximately 1.5 years after the nuclear accident were used in the present study (Fig. 7.1). The skeletal muscles of these animals were considered to contain higher levels of radioactive cesium than the new reference/regulation value in foods $(100 \mathrm{~Bq} / \mathrm{kg})$; therefore, these animals were collected and kept in the "clean feeding" livestock barns of the National Livestock Breeding Center (Fukushima, Japan). They were given non-contaminated feed and drinking water for 3 months. Between November 19, 2012 and December 12, 2012 (10 times: 10 animals for each sampling time), animals were sacrificed under deep anesthesia to collect organ samples [skeletal muscles (quadriceps muscle and psoas major muscle), liver, kidney, spleen, genital organs (ovaries or testes), blood, and urine samples]. Radioactive cesium levels were measured in each sample using a germanium semiconductor detector, and
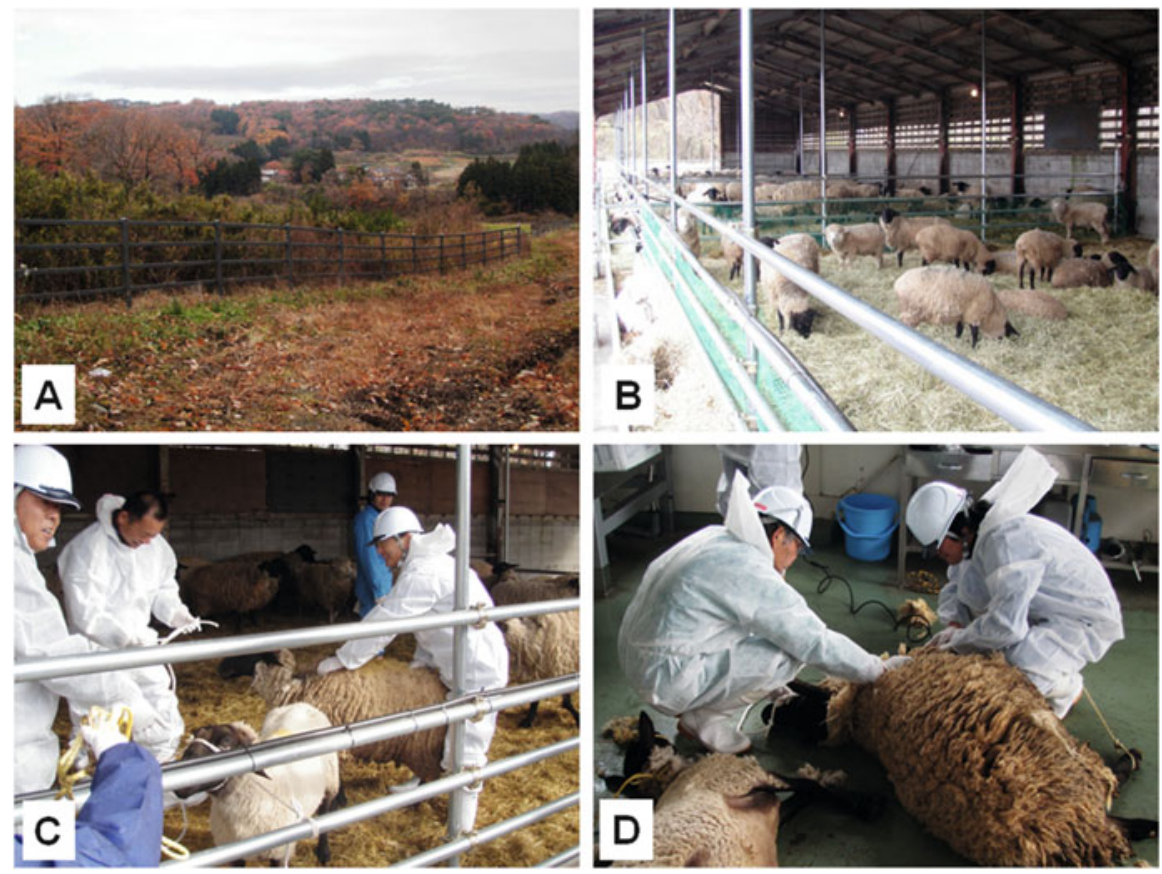

Fig. 7.1 Sheep kept in a paddock on a mountain in Fukushima prefecture ( $\sim 60 \mathrm{~km}$ from the nuclear power plant) for $\sim 1.5$ years after the accident (a). They were kept in the "clean feeding" livestock barns of the National Livestock Breeding Center and were given non-contaminated feed (b). Organ samples were collected in November and December 2012 (c and d) 
each nuclide was identified by gamma-ray spectrometry. No detectable levels of radiocesium were noted in skeletal muscles, liver, kidney, spleen, genital organs, ovaries, testes, blood, or urine samples.

After the sheep were directly exposed to radioactive radiocesium, they were given non-contaminated feed (so-called clean feeding). Radioactive cesium was found to have initially accumulated in sheep organs but was not detected 3 months later. These results confirm that "clean feeding" management was also effective for sheep.

\subsection{The Effects of "Clean Feeding" Management for Dairy Cows: Removal of Radiocesium Due to the Nuclear Power Plant Accident from Milk}

In this section, we described the effectiveness of "clean feeding" management for cows' milk. The details of this experiment have already been reported (Hashimoto et al. 2011; Manabe 2012; Manabe et al. 2011, 2013, 2014; Takahashi et al. 2012).

Changes in radiocesium levels in milk produced by cows given radiocesium contaminated feed after the nuclear accident on March 11, 2011, were examined between May 16 and June 26, 2011. Italian ryegrass, which was seeded on September 2010 and cultivated in the fields of the Animal Resource Science Center of the University of Tokyo (approximately $140 \mathrm{~km}$ south-west of the power plant), was harvested 2 months after the nuclear accident and prepared for fermented grass forage, haylage. The cows were born and kept at the Animal Resource Science Center and were given commercial mixed feed (total mixed ration forage: TMR) purchased from Zen-Noh Feed (Tokyo, Japan) that contained no radioactive iodine131, cesium-134, or cesium-137 for 2 weeks before being examined. The raw materials of TMR were as follows: $45 \%$ maize, a $29 \%$ mixture of wheat bran and rice bran, a $21 \%$ mixture of soybean oil cake and rapeseed oil cake, and $5 \%$ additives (minerals and vitamins). The feed ingredients of TMR were as follows: $16 \%$ crude protein, $2.5 \%$ crude fat, $10 \%$ crude fibers, $10 \%$ crude ash, $0.8 \%$ calcium, and $0.5 \%$ phosphorus. The cows were initially given the mixed feed of haylage and TMR at 10 and $25 \mathrm{~kg} / 600 \mathrm{~kg}$ of body weight/day, respectively for 2 weeks, and then only TMR (35 kg/600 kg of body weight/day) for 4 weeks as "clean feeding" management. During this experiment, milk was collected twice a day and mixed for each cow. The weight and radioactive cesium levels for the mixed milk from each cow were measured daily. No radioactive iodine-131 was detected in either the milk or haylage. The radiocesium level in the mixed feed of haylage and TMR was $380 \mathrm{~Bq} / \mathrm{kg}$. Four days after the initial administration of contaminated feed, radiocesium concentrations in the milk rapidly increased to $30 \mathrm{~Bq} / \mathrm{kg}$, and then equilibrated to $36 \mathrm{~Bq} / \mathrm{kg}$ after 12 days (lower than the new reference/regulation value for milk: $50 \mathrm{~Bq} / \mathrm{kg}$ ) (Table 7.3). Cows were then given TMR containing no radiocesium ("clean feeding"), and the concentrations of 
Table 7.3 Changes in radiocesium concentrations in milk

\begin{tabular}{|c|c|c|}
\hline \multirow[b]{2}{*}{ Days after initiation } & \multicolumn{2}{|c|}{ Radioactive cesium level in milk (Bq/kg) } \\
\hline & Control group & Treated group \\
\hline & Non-contaminated feed & Contaminated feed \\
\hline 0 & $\mathrm{ND}^{\mathrm{a}}$ & ND \\
\hline 2 & ND & $22 \pm 4^{\mathrm{b}}$ \\
\hline 4 & ND & $29 \pm 5$ \\
\hline 6 & ND & $33 \pm 5$ \\
\hline 8 & ND & $34 \pm 4$ \\
\hline 10 & ND & $35 \pm 6$ \\
\hline 12 & ND & $36 \pm 4$ \\
\hline \multirow[t]{2}{*}{14} & ND & $36 \pm 5$ \\
\hline & Non-contaminated feed & Non-contaminated feed \\
\hline 16 & ND & $29 \pm 3$ \\
\hline 18 & ND & $15 \pm 3$ \\
\hline 20 & ND & $12 \pm 4$ \\
\hline 22 & ND & $9 \pm 2$ \\
\hline 24 & ND & $8 \pm 3$ \\
\hline 26 & ND & $6 \pm 2$ \\
\hline 28 & ND & ND \\
\hline 42 & ND & ND \\
\hline 56 & ND & ND \\
\hline
\end{tabular}

${ }^{a}$ Not detectable: the detection limit was set to three times the standard deviation of the background ${ }^{\mathrm{b}}$ Each value represents the mean \pm standard deviation $(\mathrm{n}=6)$

radiocesium in the milk rapidly decreased, with undetectable levels (less than $5 \mathrm{~Bq} /$ $\mathrm{kg}$ : background level) noted 14 days after the initial administration of the non-contaminated feed. Concentrations of radiocesium in milk were then maintained at the background level. When cows (body weights $\sim 600 \mathrm{~kg}$ ) were given contaminated feed $(12,600 \mathrm{~Bq} / 600 \mathrm{~kg}$ body weight/day), $5.71 \%$ of radiocesium was secreted into the milk $(720 \mathrm{~Bq} / 20 \mathrm{~kg}$ milk/day). The transfer coefficient $(\mathrm{Fm})$ for the transfer of radiocesium from cow feed to milk was calculated according to the following formula: $\mathrm{Fm}($ day $/ \mathrm{L})=$ radiocesium level in milk $(\mathrm{Bq} / \mathrm{L}) /$ the intake of radiocesium by each cow $(\mathrm{Bq} / \mathrm{cow} /$ day) (Hashimoto et al. 2011; Manabe et al. 2013, 2014; Takahashi et al. 2012). The radiocesium Fm value was 0.0029 (day/L) at the highest point of radiocesium levels in the milk.

Generally, infants and schoolchildren consume milk daily; therefore, advanced safety measures are necessary to ensure that milk contains extremely low levels of radiocesium. It is thus essential that cows do not orally ingest feed contaminated with radioactive cesium. Further research is needed to ensure the safety of domestically produced milk. The dynamics of more than $90 \%$ of the radiocesium contained in polluted feed that is not secreted into the milk needs to be elucidated in more detail. It is currently unknown whether radioactive cesium that is taken into the cow body is rapidly excreted through the feces, urine, sweat, or bile. Nor do we know where, or in which organs, or how much radiocesium accumulates in the cow 
body if it is not rapidly excreted. We do not know whether the radioactive cesium that accumulates in a cow's body is transferred to milk. Further studies are needed to understand the molecular mechanisms regulating cesium secretion into milk in dairy cows. The concentrations of various components including minerals in milk are strictly maintained within a constant range in mammals, and cesium is also strictly controlled. The concentrations of potassium, an essential element, are maintained at approximately $1.5 \mathrm{mg} / \mathrm{g}$ in cow's milk. The dynamics of cesium in organisms is considered to be similar to those of potassium. If the secretion dynamics of cesium into milk are similar to those of potassium, radioactive cesium levels in milk may also be maintained at a certain level. Further research is needed not only for the reconstruction of livestock industries, which were debilitated by the nuclear power plant accident, but also for the protection and improvement of the health of the Japanese people.

In conclusion, dairy cows given radiocesium-contaminated feed produced milk that was contaminated with radiocesium. When these cows were given non-contaminated feed (so-called clean feeding), radioactive cesium levels in milk rapidly decreased and reached undetectable levels after 4 weeks. These results confirm that "clean feeding" management is also effective for dairy cows.

\subsection{Conclusion}

In the present studies, we demonstrated the effects of "clean feeding" management on livestock products that were contaminated with radioactive cesium due to the Fukushima Daiichi nuclear power plant accident in March 2011. Radiocesiumcontamination in animal products represents an important potential route of exposure in the human food chain; therefore, the development solutions reduce and combat radiocesium-contamination is a serious social issue in Japan. Most farm animals are kept in closed barns in Japan, which reduced the initial contamination of animal products by radioactive nuclides in the early phase of the nuclear power plant accident. Moreover, pigs and chickens in Japan were given imported feed that was not contaminated by radioactive nuclides. However, adequate amounts of grass feed, at least $30 \%$ or more of the total feed, are essential for rearing herbivorous animals (such as horses, sheep, and cattle), and uncontaminated grass feed and/or forage containing acceptable amounts of radiocesium are needed. The present results concerning products from horses, sheep, and cattle revealed that no detectable level of radiocesium was noted in the products (meat or milk) of herbivores that received radiocesium-contaminated feed, followed by non-contaminated feed, a livestock management system called "clean feeding". In conclusion, "clean feeding" management plays a crucial role in solving this social problem.

Open Access This chapter is distributed under the terms of the Creative Commons Attribution Noncommercial License, which permits any noncommercial use, distribution, and reproduction in any medium, provided the original author(s) and source are credited. 


\section{References}

Beresford NA, Howard BJ (2011) An overview of the transfer of radionuclides to farm animals and potential countermeasures of relevance to Fukushima releases. Integr Environ Assess Manag 7:382-384

Hashimoto K, Tanoi K, Sakurai K, Hashimoto T, Nogawa N, Higaki S, Kosaka N, Takahashi T, Enomoto Y, Onoyama I, Li JY, Manabe N, Nakanishi T (2011) The radioactivity measurement of milk from the cow supplied with pasture grown in Ibaraki-prefecture, after the Fukushima nuclear power plant accident. Radioisotopes 60:335-338

Howard BJ, Beresford NA, Voigt G (2001) Countermeasures for animal products: a review of effectiveness and potential usefulness after an accident. J Environ Radioact 56:115-137

International Atomic Energy Agency (IAEA) (1997) The use of Prussian blue to reduce radiocesium contamination of milk and meat produced on territories affected by the chernobyl accident, IAEA $=$ TECDOC-926. IAAEA, Vienna

International Atomic Energy Agency (IAEA) (2005) Environmental consequences of the chernobyl accident and their remediation: twenty years of experience report of the UN chernobyl forum Expert Group "Environment” (EGE). IAEA, Vienna

Manabe N (2012) Metabolism of radioactive cesium in dairy cows. Chem Biol 50:668-670

Manabe N, Li JY, Takahashi T, Endo M, Enomoto Y, Tanoi K, Sakurai K, Nakanishi T (2011) Transition to the milk of radioactive materials in feed for dairy cattle and future pollution control. Dairy Jpn 12:25-27

Manabe N, Takahashi T, Li JY, Tanoi KM, Nakanishi T (2013) Changes in the transfer of fallout radiocesium from pasture harvested in Ibaraki prefecture, Japan, to cow milk two months after the Fukushima Daiichi nuclear power plant accident. Springer, Germany

Manabe N, Takahashi T, Li JY, Tanaka T, Tanoi K, Nakanishi T (2014) Farm animals and livestock products contamination with radioactive cesium due to the Fukushima Daiichi nuclear power plant accident. Sustain Livest Prod Hum Welf 68:1085-1090

Nisbet AF, Brown J, Howard BJ, Beresford NA, Ollagnon H, Turcanu C, Camps J, Andersson K, Rantavaara A, Lkaheimonen T, Duranova T, Oughton D, Kirchner G, Papachristodoulou C, Ioannides K, Kwakman P (2010) Decision aiding handbooks for managing contaminated food production systems, drinking water and inhabited areas in Europe. Radioprotection 45:S23-37

Pearce J (1994) Studies on any toxicological effects of Prussian blue compounds in mammals: a review. Food Chem Toxicol 32:577-582

Takahashi T, Enomoto Y, Endo M, Onoyama I, Tomimatsu S, Ikeda M, Li JY, Tanoi K, Nakanishi T, Manabe N (2012) Changes in radionuclide levels in milk from the cow supplied with pasture grown in Ibaraki prefecture, after the accident in Fukushima Daiichi nuclear power plant. Radioisotopes 61:551-554 